\title{
The fourth decade (1993-2003)
}

Enric Vallduvi and Elisabet Engdahl, The linguistic realization of information packaging. Linguistics 1996, Volume 34, issue 3, 459-519. [Special issue: A Key Concept for Translation Theory, edited by Monika Doherty] DOI 10.1515/ling.1996.34.3.459

\section{Introductory comments by the authors}

This article originated from the need to consolidate a language-independent common ground for the discussion of information packaging in natural language, i.e., the way speakers structure utterances, by syntactic, prosodic or morphological means, in order to make the information conveyed fit the hearer's mental model of the current conversation. At the time it had become apparent to us that attempts to advance in the study of information packaging were hampered by two substantial obstacles. One was the terminological quagmire: the terms focus, topic, theme, rheme, background, presupposition, and so on were being used at the time in varied and mutually contradictory ways. The other was the fact that very often linguists had an exclusive language-particular "bottom up" approach to the study of information packaging: from a single structural category or dimension (prosodic, syntactic or morphological) in a single language, conclusions were drawn about the pragmatic meaning (a.k.a. discourse function) associated with that category. A side effect of this was that in any discussion on what were the basic interpretive categories needed for a full description of information packaging in natural language there was continued interference from languageparticular structural "biases". This, in turn, led to what in pattern-recognition terms would be errors of both precision (incorrectly identifying as informational apples things that are informational oranges simply because in language $L$ their structural realization is conflated) and recall (incorrectly missing a subset of informational tokens simply because in language $L$ this subset fails to be expressed structurally).

"The linguistic realization of information packaging" addresses both of the aforementioned obstacles, but the emphasis is mostly on the second one. The aim of the paper was to equip the linguistic community with a tool that would allow a "top down" look at the form-meaning relation in the domain of information packaging: a clearly defined language-independent ontology and a simple combinatorial semantics for information packaging. Thus, in studying the interface between structure and information packaging, researchers could work both 
"bottom up", from structural category to informational meaning, and "top down", from informational category to structural realization, producing both more accurate language-particular analyses and more comprehensive crosslinguistic overviews. The article presents a "top down" crosslinguistic comparison of structurally diverse languages, which at the time was quite a novel contribution. In addition, it contains a number of pointers to further research, both very specific (e.g., the interpretation of particular configurations in particular languages) and very general (e.g., differences in the expression of information packaging in VO vs. VO languages).

In the conclusion of the article, after a summary of the crosslinguistic findings that surfaced from the application of the "top down" paradigm, we expressed the hope that these findings "should suffice to illustrate the advantages of using a systematic description of informational meaning [. . . ] in the contrastive study of language." In addition, it seems that the article has contributed towards raising linguists' awareness of the need for language-independent categories for the interpretation of recalcitrant terms like focus, background and topic. Having such a foundation is, of course, essential for comparative work on different aspects of context-dependent meaning and its expression in typologically diverse languages.

Enric Vallduví: Universitat Pompeu Fabra. E-mail: enric.vallduvi@upf.edu

Elisabet Engdahl: University of Gothenburg. E-mail: elisabet.engdahl@svenska.gu.se 